\section{Cureus}

Received 01/08/2016

Review began 01/13/2016

Review ended 01/26/2016

Published 02/04/2016

\section{C) Copyright 2016}

Vaishya et al. This is an open access article distributed under the terms of the Creative Commons Attribution License CC-BY 3.0., which permits unrestricted use, distribution, and reproduction in any medium, provided the original author and source are credited.

\title{
Extensor Mechanism Disruption after Total Knee Arthroplasty: A Case Series and Review of Literature
}

\author{
Raju Vaishya ${ }^{1}$, Amit Kumar Agarwal ${ }^{1}$, Vipul Vijay ${ }^{1}$ \\ 1. Department of Orthopedics, Indraprastha Apollo Hospital, New Delhi
}

$\square$ Corresponding author: Amit Kumar Agarwal, amitorthopgi@yahoo.co.in

Disclosures can be found in Additional Information at the end of the article

\section{Abstract}

Extensor mechanism disruption following total knee arthroplasty (TKA) is a rare but devastating complication. These patients may require revision of the implants, but even then, it may not be possible to restore the normal function of the knee after the disruption. The patterns of extensor mechanism disruption can broadly be classified into three types: suprapatellar (quadriceps tendon rupture), transpatellar (patellar fracture), or infrapatellar (patellar tendon rupture). Infrapatellar tendon ruptures are the worst injuries, as they carry maximum morbidity and are challenging to manage. The disruption of the extensor mechanism may occur either intra-operatively or in the immediate postoperative period due to an injury. The treatment of extensor mechanism complications after TKA may include either nonsurgical management or surgical intervention in the form of primary repair or reconstruction with autogenous, allogeneic, or synthetic substitutes. We have provided an algorithm for the management of extensor mechanism disruption after TKA.

Categories: Orthopedics

Keywords: extensor mechanism disruption, total knee arthroplasty, quadriceps tendon rupture

\section{Introduction}

Extensor mechanism disruption is one of the reported reasons for revision surgery after total knee arthroplasty (TKA) with the incidence of $0.17-1.4 \%$ [1]. It is also a frequent source of postoperative morbidity. The extensor mechanism includes the quadriceps muscle and tendon, medial and lateral retinaculum, patellofemoral and patellotibial ligaments, patella, patellar tendon, and tibial tubercle. Discontinuity in any of these components can lead to an extensor mechanism disruption and render an otherwise perfectly good TKA useless. Extensor mechanism-related complications can occur either intraoperatively or postoperatively. Commonly reported causes during the surgery include avulsion or tendon injury during the exposure, improper patellar resection, and damage to the blood supply due to injudicious lateral retinacular release or multiple prior surgeries. The postoperative causes may include tissue necrosis arising from infection, component malalignment, and trauma. Various treatment options are available for managing these challenging problems, and recent advances in alternative reconstruction techniques have yielded promising results [2]. We are presenting our experience of 10 knees (nine cases) with extensor mechanism disruption following TKA.

\section{Materials And Methods}

In a retrospective study, we present a series of nine cases (with 10 knees) of extensor mechanism rupture associated with TKA. All the patients who had primary TKA during 2000- 


\section{Cureus}

2014 by the senior author were reviewed. Informed patient consent was obtained at the time of treatment. Out of 5,254 patients, nine were found to have extensor mechanism disruption following TKA. All these primary TKAs were done using a midline anterior (modified Insall's) approach, using a posterior stabilized cemented prosthesis, Scorpio ${ }^{\mathrm{TM}}$ Single Axis Total Knee System (Stryker, Kalamazoo, MI).

\section{Results}

Complications involving the extensor mechanism occur in $1 \%$ to $12 \%$ of patients following primary TKA. The average age of the patient was 59.6 years (range: 32 - 72 years). There were seven females and two males. One patient had an injury to both the knees. Four patients had rheumatoid arthritis (RA) and five had osteoarthritis (OA) as their primary diagnosis. All the patients were operated using a midline medial parapatellar approach, except one with a severe valgus deformity who was exposed by a lateral parapatellar approach. The average duration of injury since primary surgery was 8.16 weeks (range: 1 - 24 weeks). Most patients have had trivial domestic injuries due to falling on stairs or a floor, injuries due to forceful bending of the knees during exercise, or while sitting down on the toilet. One patient with RA had severe knee stiffness preoperatively with a range of motion (ROM) of 10-20 degrees. This patient sustained a patellar fracture three months postoperatively due to forceful bending of the knee while doing exercises (Figure 1).

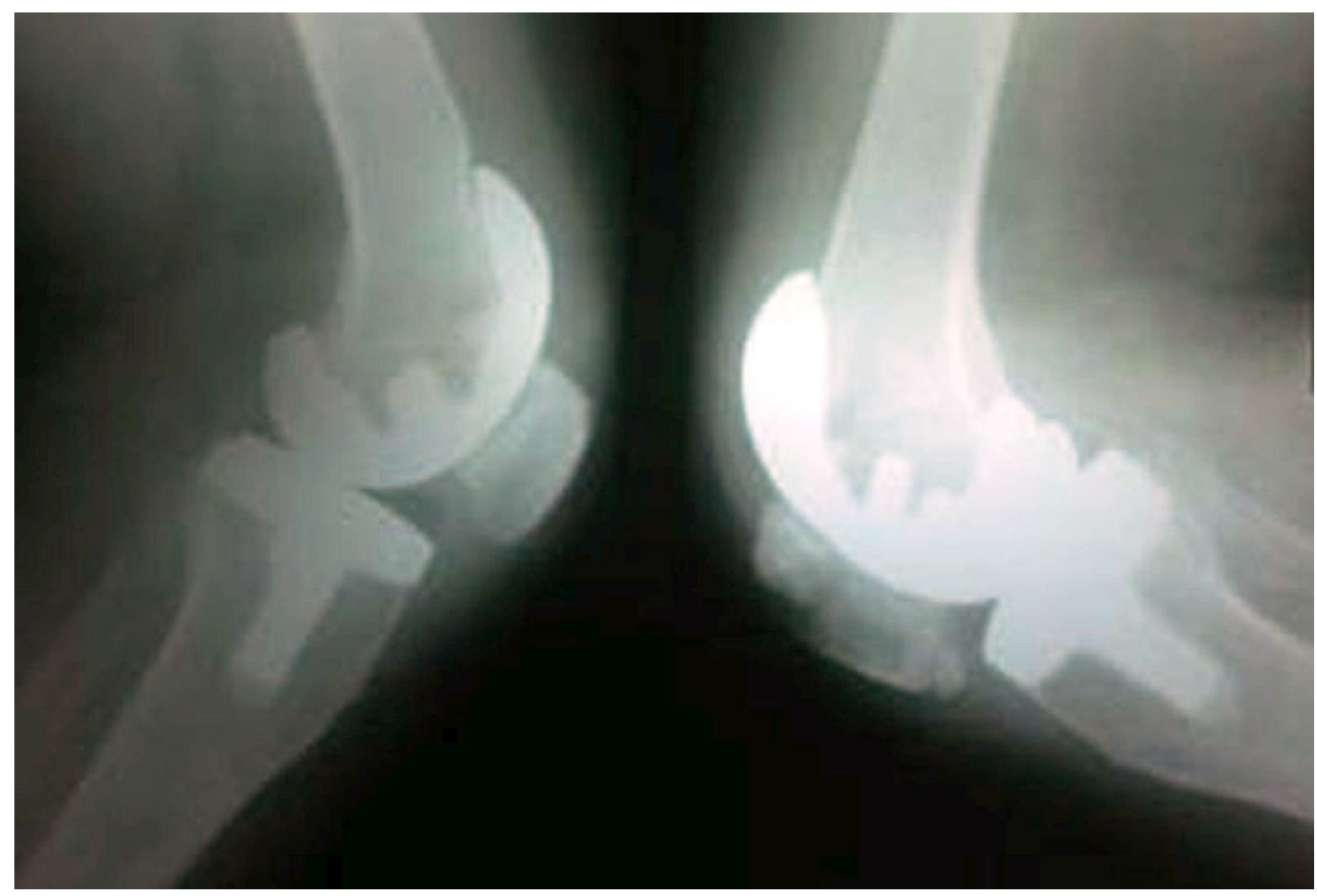

FIGURE 1: Lateral radiograph of a patient with a left patellar fracture three months after total knee arthroplasty

One patient with OA sustained an intraoperative injury to the patella while everting the patella with a towel clip that led to the crushing of osteoporotic bone and subsequent fracture within one week of surgery. One patient with bilateral TKA incurred injuries to both the knees following a fall from some stairs and sustained a lateral patellar dislocation on one side (Figures 2-3) and a patellar fracture on the other side (Figure 4). 


\section{Cureus}

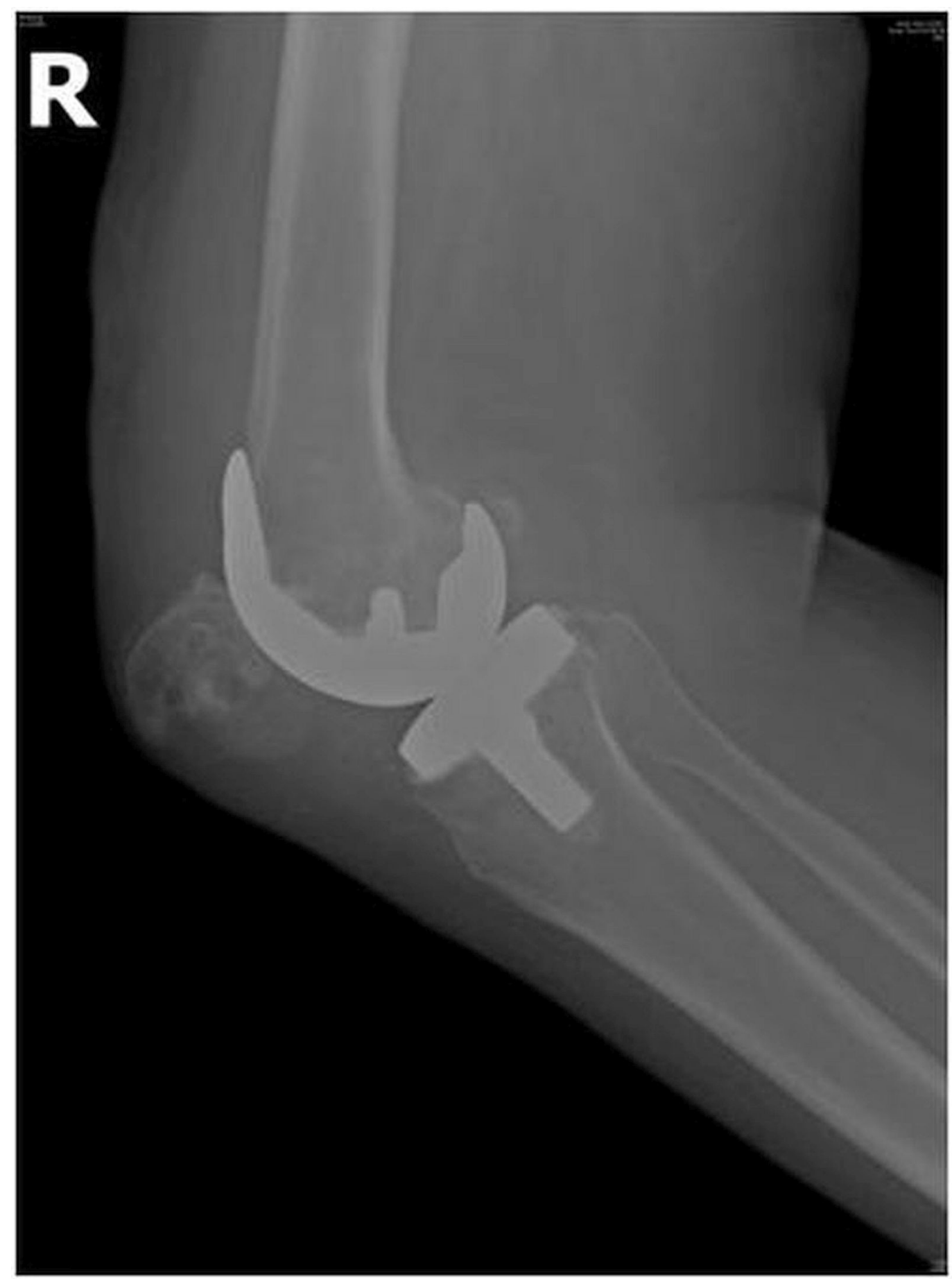

FIGURE 2: Lateral radiograph of a patient showing lateral patellar dislocation on the right side after TKA. 


\section{Cureus}

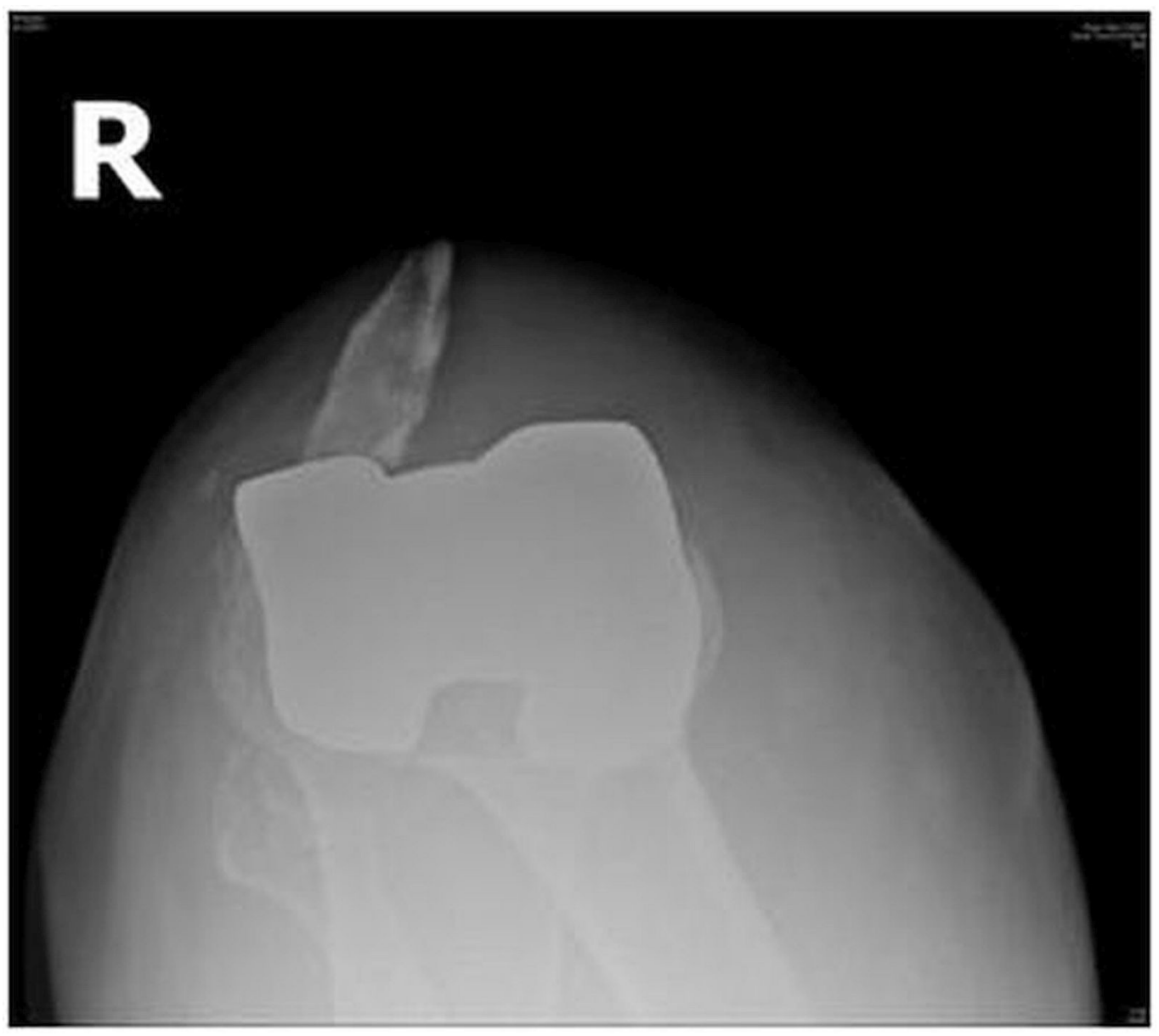

FIGURE 3: Merchant view of a patient showing a lateral patellar dislocation on the right side after TKA. 


\section{Cureus}

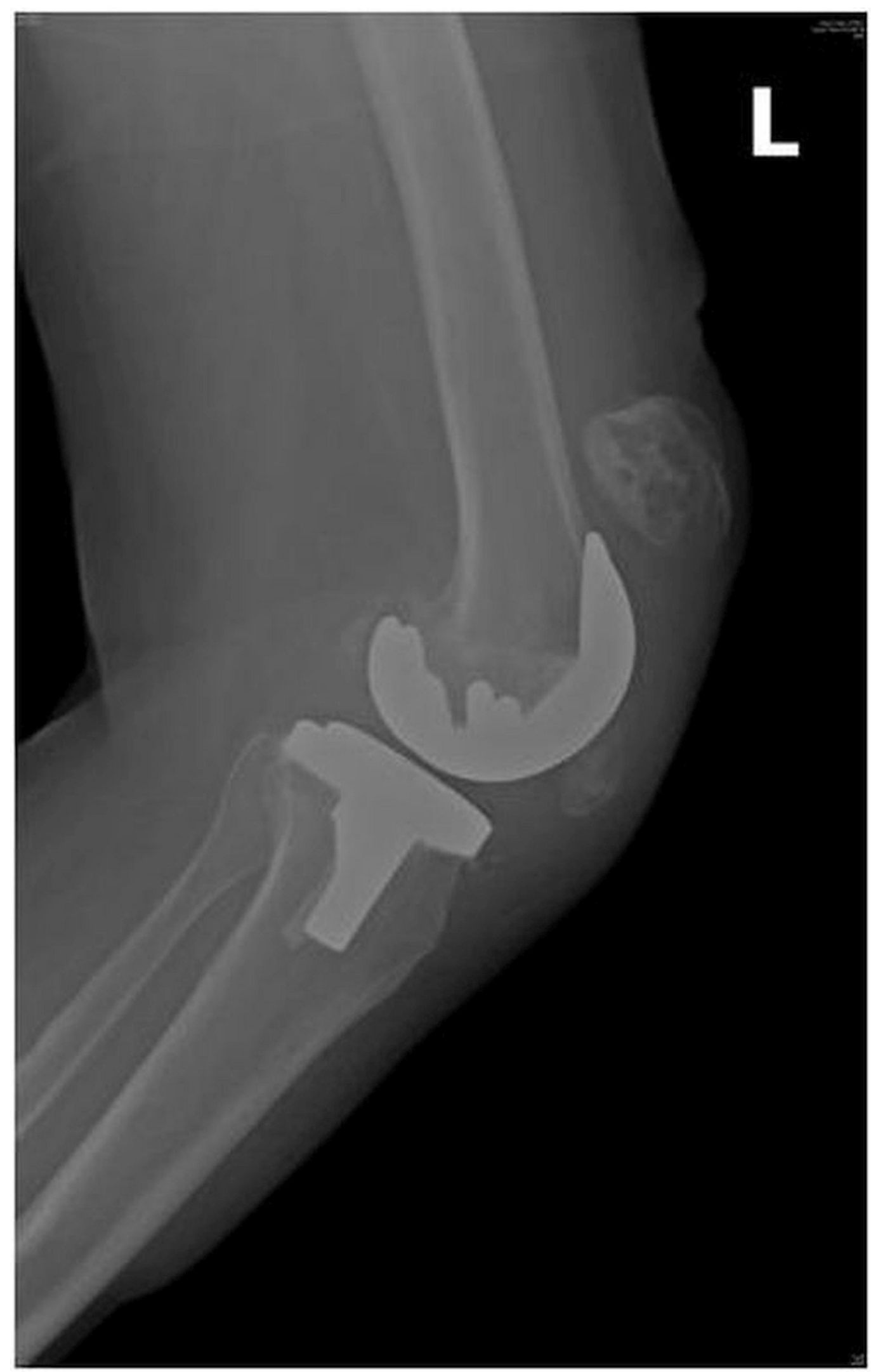

FIGURE 4: Lateral radiograph of a patient showing a patellar fracture on the left side after TKA 


\section{Cureus}

Out of 10 knees, five knees had a fractured patella, two sustained infrapatellar tendon ruptures (Figure 5), one developed a lateral patellar dislocation, and the remaining two sustained a rupture of the quadriceps muscle in the suprapatellar region. Seven out of 10 knees were operated upon while three were treated conservatively (Table 1).

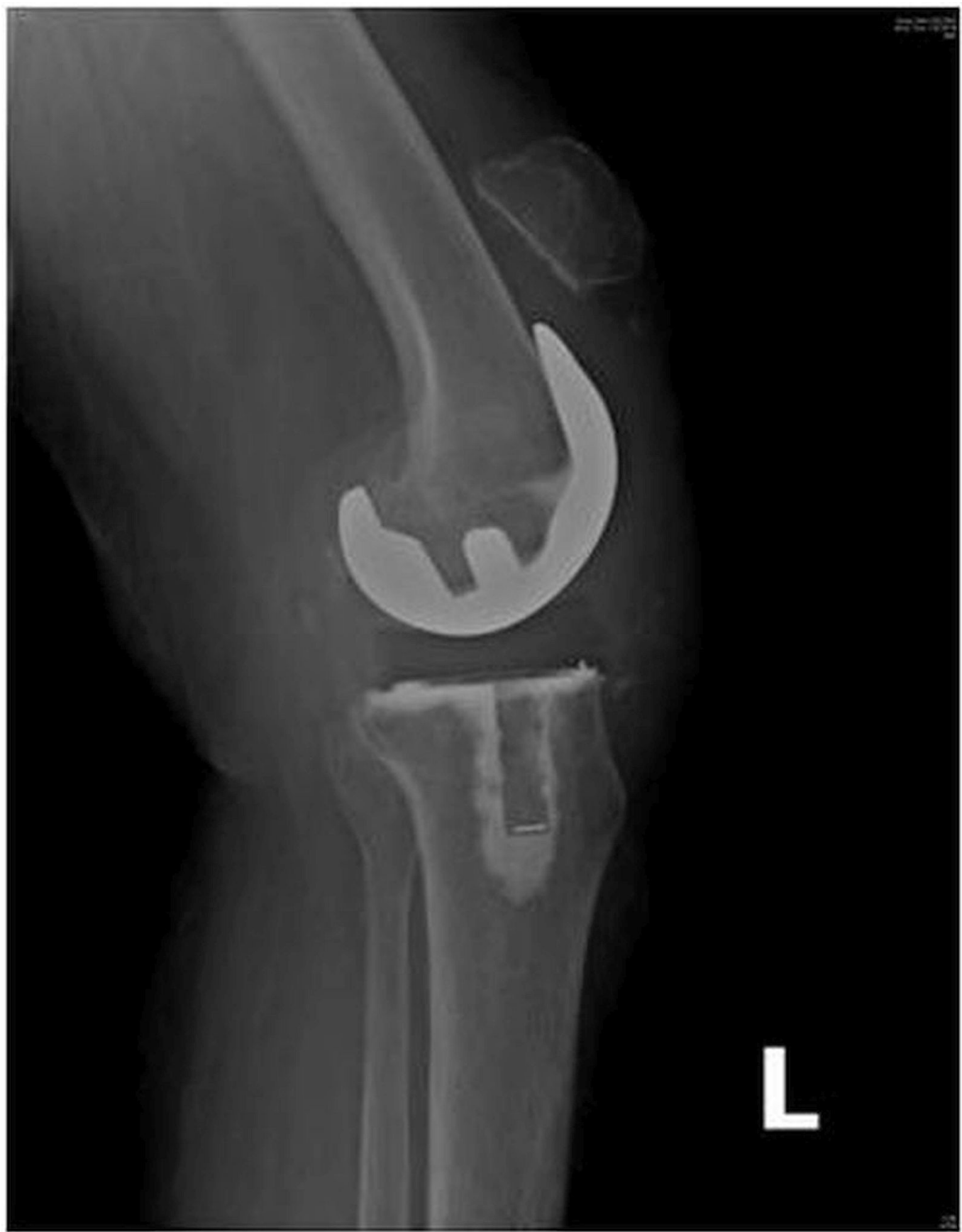

FIGURE 5: Lateral radiograph of a patient showing an infrapatellar tendon rupture and proximal migration of the left patella. 


\section{Cureus}

\begin{tabular}{|c|c|c|c|c|c|c|c|c|}
\hline $\begin{array}{l}\text { S. } \\
\text { No. }\end{array}$ & $\begin{array}{l}\text { Age \& } \\
\text { Sex }\end{array}$ & Dx & $\begin{array}{l}\text { Mechanism of } \\
\text { Injury }\end{array}$ & Rupture Site & Treatment & $\begin{array}{l}\text { Follow-up } \\
\text { Duration }\end{array}$ & $\begin{array}{l}\text { Extensor } \\
\text { Lag }\end{array}$ & R.O.M. \\
\hline 1 & $72 / \mathrm{F}$ & R.A & $\begin{array}{l}\text { Trauma due to } \\
\text { fall }\end{array}$ & Infrapatellar & $\begin{array}{l}\text { Reconstruction autologous } \\
\text { semitendinosus graft. }\end{array}$ & 6 months & $45 \mathrm{deg}$. & $\begin{array}{l}0-100 \\
\text { deg }\end{array}$ \\
\hline 2 & $56 / \mathrm{M}$ & O.A & $\begin{array}{l}\text { Trauma due to } \\
\text { fall }\end{array}$ & Suprapatellar & Direct repair & 9 months & $10 \mathrm{deg}$. & $\begin{array}{l}0-120 \\
\text { deg }\end{array}$ \\
\hline 3 & 65/M & O.A & $\begin{array}{l}\text { Trauma due to } \\
\text { fall }\end{array}$ & Parapatellar & Lateral retinacular release & 12 months & 10 deg. & $\begin{array}{l}5-100 \\
\text { deg }\end{array}$ \\
\hline 4 & 65/M & O.A & $\begin{array}{l}\text { Trauma due to } \\
\text { fall }\end{array}$ & Transpatellar & $\begin{array}{l}\text { Intra-osseus and retinacular } \\
\text { repair. }\end{array}$ & 12 months & 20 deg. & $\begin{array}{l}10-90 \\
\text { deg }\end{array}$ \\
\hline 5 & $68 / F$ & O.A & $\begin{array}{l}\text { Trauma due to } \\
\text { fall }\end{array}$ & Infrapatellar & $\begin{array}{l}\text { Knee brace (patient refused } \\
\text { surgery) }\end{array}$ & 13 months & 30 deg. & $\begin{array}{l}0-120 \\
\operatorname{deg}\end{array}$ \\
\hline 6 & $32 / \mathrm{F}$ & R.A. & $\begin{array}{l}\text { Forceful } \\
\text { bending of } \\
\text { knee }\end{array}$ & Transpatellar & Knee brace & 16 months & $10 \mathrm{deg}$. & $\begin{array}{l}0-45 \\
\text { deg }\end{array}$ \\
\hline 7 & $55 / F$ & O.A & Intraop & Transpatellar & Knee brace & 6 months & $15 \mathrm{deg}$. & $\begin{array}{l}0-100 \\
\text { deg. }\end{array}$ \\
\hline 8 & $67 / F$ & R.A. & $\begin{array}{l}\text { Forceful } \\
\text { bending of } \\
\text { knee }\end{array}$ & Suprapatellar & Direct repair & 8 months & 10 & $\begin{array}{l}0-110 \\
\text { deg }\end{array}$ \\
\hline 9 & $52 / \mathrm{F}$ & R.A. & $\begin{array}{l}\text { Forceful } \\
\text { bending of } \\
\text { knee }\end{array}$ & Transpatellar & TBW & 12 months & 10 & $\begin{array}{l}0-120 \\
\text { deg }\end{array}$ \\
\hline 10 & $64 / F$ & OA & $\begin{array}{l}\text { Forceful } \\
\text { bending of } \\
\text { knee }\end{array}$ & Transpatellar & TBW & 14 months & 10 & $\begin{array}{l}0-100 \\
\text { deg }\end{array}$ \\
\hline
\end{tabular}

TABLE 1: Table showing a series of nine cases (with 10 knees) of extensor mechanism rupture associated with total knee arthroplasty

Three out of five patients with patellar fracture were treated by open reduction and internal fixation (ORIF) of the patellae with tension band wiring. Two out of five patients underwent a direct repair with an Ethibond $\# 5$ suture done for the rupture of the quadriceps mechanism. A lateral retinacular release was performed on one knee while reconstruction of the infrapatellar tendon was done on the other knee using the ipsilateral hamstring (gracilis) tendon (Figure 6). 


\section{Cureus}

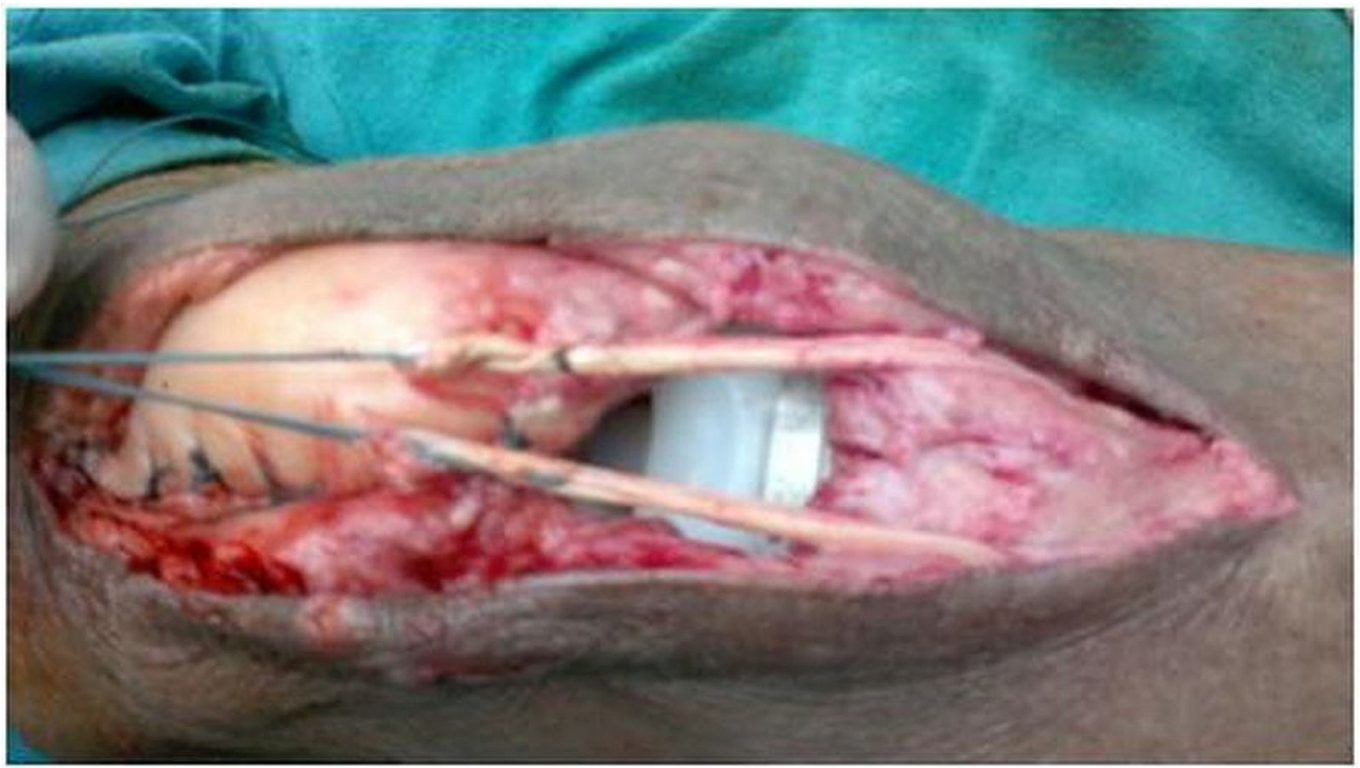

FIGURE 6: Intraoperative picture showing an infrapatellar tendon reconstruction using an ipsilateral hamstring (gracilis) tendon.

A drill hole of $4.5 \mathrm{~mm}$ was made through the tibia at the tibial tuberosity level as well as another hole made through the patella in the mediolateral direction. The harvested tendon was passed through these drill holes and sutured back to itself and further anchored to the surrounding soft tissues. An above-the-knee cast was applied for one month followed by physiotherapy exercises. At the six-month follow-up, there was no recurrence of the dislocation and the ROM was up to 100 degrees flexion, but with an extensor lag of 45 degrees (Figure 7 ).

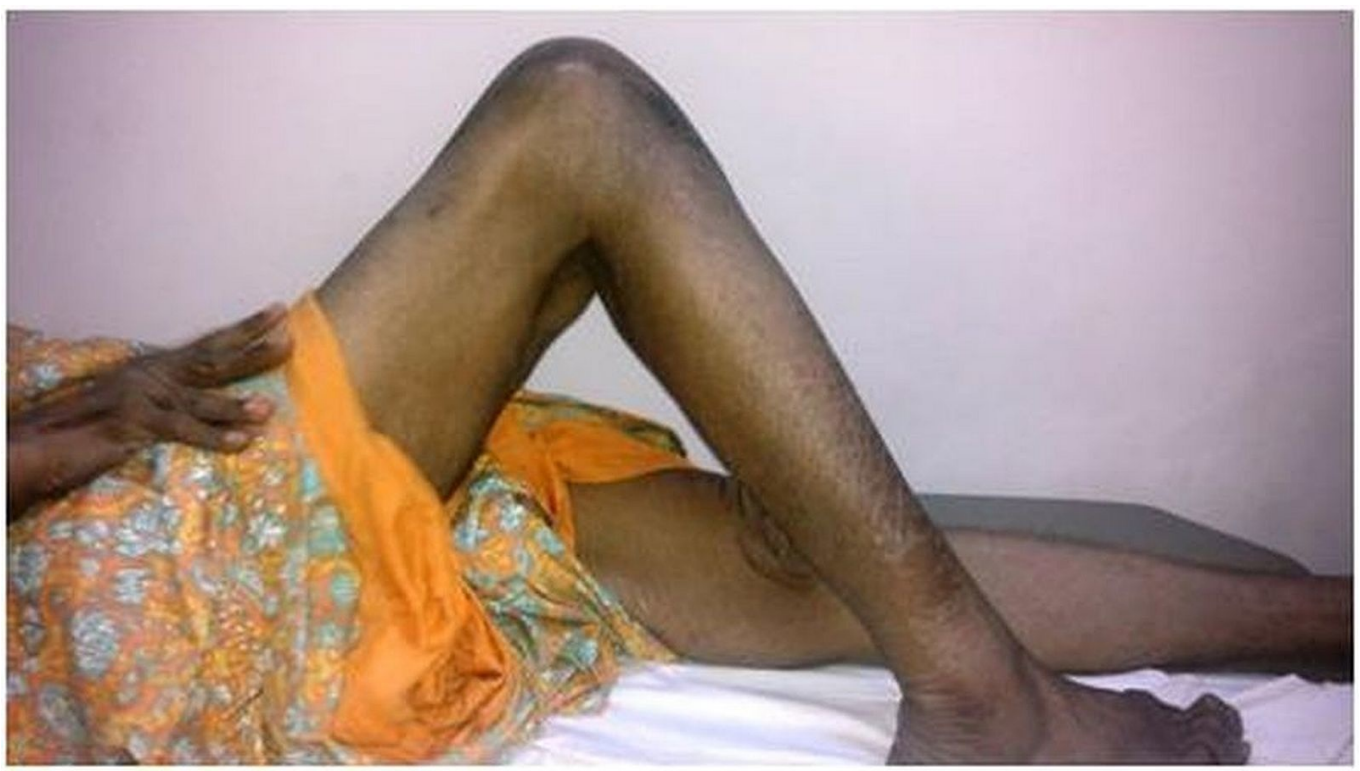

FIGURE 7: Clinical picture at six months follow-up, after infrapatellar tendon reconstruction showing a ROM with up to 100 degrees flexion. 
All of these nine patients were followed up for six to 16 months (average: 10.57 months) and were found to have some degree of extensor lag, ranging from 10 to 45 degrees (average: 20 degrees). The patients with infrapatellar tendon ruptures had that maximum lag while the suprapatellar lesions produced the least lag (Table 1). The average ROM after treatment of the extensor mechanism was 94.5 degrees (range: 0-120 degrees).

\section{Discussion}

Disruption of the extensor mechanism after TKA may result in a) patellar fracture and b) rupture of either the quadriceps tendon or c) the patellar tendon (PT). Our experience of extensor mechanism disruption after primary TKA is similar to that which is reported in the literature. Extensor mechanism rupture following TKA is a rare (0.7-2.7\%), albeit devastating, complication [3]. If untreated, it leads to the inability of the patient to ambulate without a significant brace support or ambulatory aids and an ultimate early failure of TKA.

Proper surgical management of extensor mechanism disruption remains controversial. The treatment options for the repair of PT include observation, direct primary repair, or reconstruction with a synthetic ligament, autograft, or allograft tissue [4]. All these treatment options have been reported with inconsistent results. A direct repair is often difficult or not possible, due to poor quality and an inadequate amount of tendon tissue [5]. Hence, PT reconstruction is required in these cases, using either autograft (e.g., hamstring tendons) or allografts. Allografts seem a simple solution to reconstruct the disrupted PT adequately. Options for allograft reconstruction include either an Achilles tendon bone block allograft or a whole extensor mechanism allograft. Surgical principals include rigid fixation of the hostallograft junction, coverage of the allograft tissue with as much autogenous tissue as possible, tensioning the graft in full extension, and avoid testing the repair. With proper surgical technique and rehabilitation, patients show acceptable functional outcome for this devastating complication [6].

Some stable and undisplaced fractures of the patella can be managed nonsurgically [7]. Displaced fractures of patella or tendon rupture often lead to poor results. Patellar fractures after TKA are not very common. The factors considered for treatment include a) integrity of the extensor mechanism, b) fixation status of the patellar implant, and c) quality of the bone. Stable fractures associated with a stable implant can be treated successfully with nonoperative means with minimal complications. When operative treatment is required, it is often associated with a high rate of complications and surgeries. Patellar clunk, soft-tissue adhesions, prosthetic wear or loosening, and osteonecrosis are the other possible complications [8].

Quadriceps tendon tears associated with TKA are more difficult to treat and associated with a poor prognosis than quadriceps tendon tears in the native knee. Tears of the quadriceps tendon following TKA are less frequent, and only a few reports have addressed this complication [9]. While a single traumatic episode may result in a quadriceps tendon tear, systemic diseases, such as rheumatoid arthritis, diabetes mellitus, chronic renal failure, obesity, and hyperthyroidism, may predispose an individual to this injury. Local factors, such as prior knee arthroplasty, arthrotomy, multiple steroid injections into the knee, poor patellar positioning, and lateral retinacular release at the time of the total knee arthroplasty, have been associated with tears of the quadriceps tendon after TKA. In patients with a TKA, however, the results after primary repair of a complete quadriceps tendon tear have been less predictable, and no recommendations for the treatment of a partial quadriceps tear following TKA have been proposed. 
In a study of 11 patients who had a complete rupture of the quadriceps tendon, nine had an identifiable predisposing systemic or local factor that may have contributed to the tear. Only four of these 11 patients ultimately rated the outcome as satisfactory. Four of the 10 patients had a re-rupture of the quadriceps tendon after operative repair. Two patients had a deep periprosthetic infection develop and the TKA was removed. One of those two patients later had an above-the-knee amputation to control the infection.

In a review of 281 TKAs over a six-year period that included patellar resurfacing, there were 28 (10\%) complications related to extensor mechanism: three quadriceps tendon ruptures, five patellar fractures, four PT ruptures, 11 recurring patellar subluxations, four cases of patellar pain, and one mal-rotated patella. Patellar fractures occurred mainly in patients who had RA. Patients with patellar instability had abnormal valgus deformities of their knees preoperatively. These patients presented with subluxation problems at an average of four months after surgery. The quadriceps tendon tear after TKA occurs in about $0.1 \%$ cases. We agree that the outcomes are poor for patients who have a complete quadriceps tendon tear after TKA. Suprapatellar ruptures in the quadriceps muscle could be due to improper repair of the quadriceps muscle or tendon during closure and may lead to failure with trauma. These ruptures can be repaired directly and are associated with good results and minimal extensor lag.

Our choice of reconstruction is the hamstring tendon autograft, as they are readily available locally around the knee and are free for the patient [10]. The selection of allografts is compounded by many inherent problems, such as non-universal availability, high cost, the possibility of disease transmission, and doubtful incorporation. The patients who sustain a partial tear could be successfully treated non-operatively without many complications and have uniformly good outcomes. Amongst all types of ruptures, it has been found historically that the infrapatellar ruptures of the patellar tendon are associated with poor results and have maximum extensor lag postoperatively.

In TKA, most complications related to the extensor mechanism are reportedly caused by patellar maltracking or instability. Patellar maltracking may result from component malposition and limb malalignment, prosthetic design, improper patellar preparation, or softtissue imbalance. Patellofemoral instability commonly occurs from malrotation of the femoral or tibial components. Although plain (axial) radiographs may display the lateral subluxation of the patella, only computed tomography (CT) can quantify rotational malalignment of the components. Nonsurgical treatment is unsuccessful. A revision surgery is advised for major malposition of components. In the absence of component malposition, proximal soft tissue realignments (lateral patellar retinacular release) or tibial tubercle transfers have been used. Surgical repair or reconstruction of PT itself may risk rupture of the extensor mechanism. From our experience, we found that an injury in the first few weeks following an arthroplasty poses a maximum risk of extensor mechanism rupture. Intraoperative care must be taken to avoid an extensor mechanism injury like forceful eversion of the patella (using towel clips in a soft bone). We have provided an algorithm for management of extensor mechanism disruption after TKA (Figure 8). 


\section{Cureus}

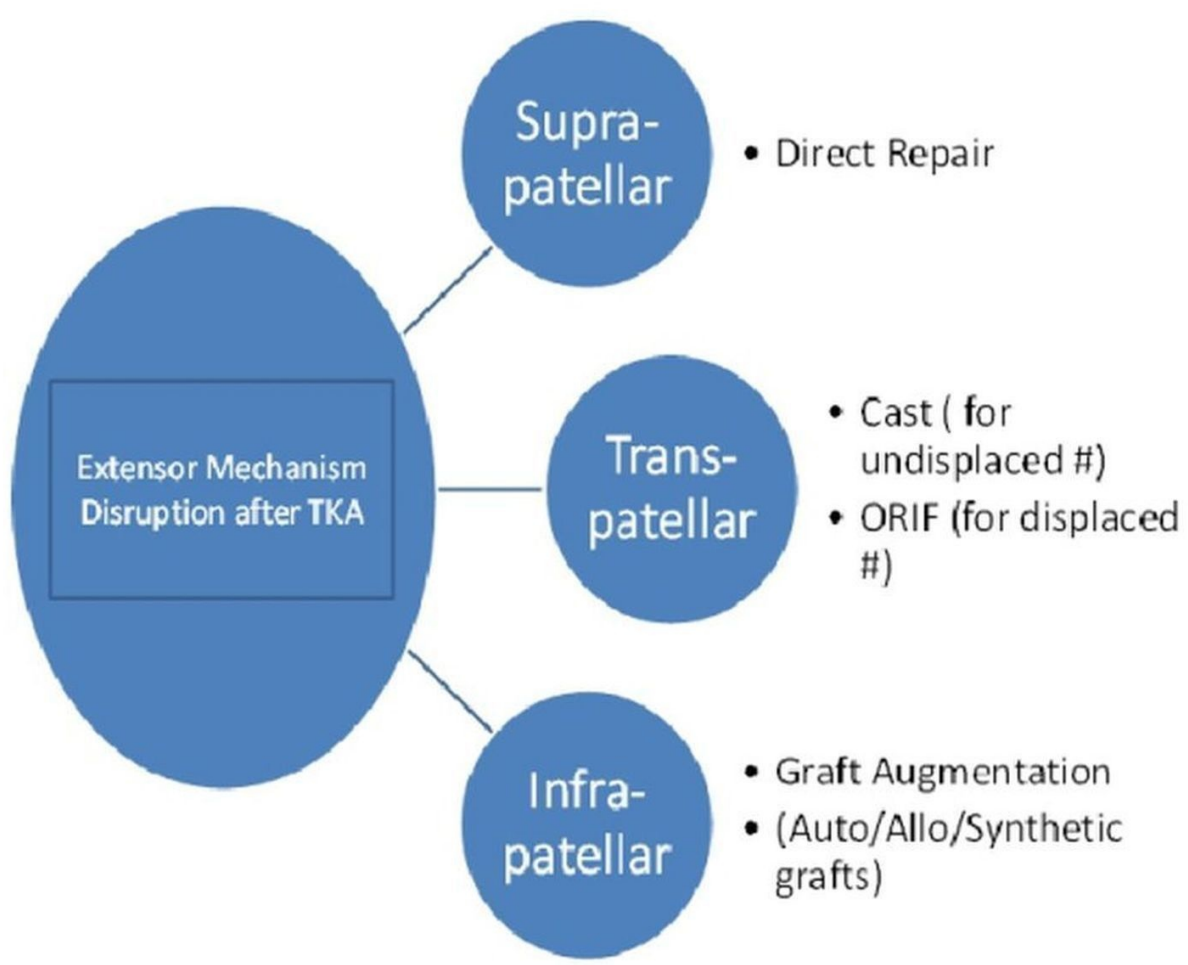

\section{FIGURE 8: Algorithm for management of an extensor mechanism disruption after total knee arthroplasty}

Increased understanding of biomechanics, implant designs and alignment, rotation, and softtissue balance has resulted in a decrease in extensor mechanism-associated complications after TKA. Appropriate prosthetic selection and meticulous surgical technique remain the keys to avoiding unsatisfactory results and revision surgery.

\section{Conclusions}

Extensor mechanism disruption as a result of patellar tendon, quadriceps tendon rupture, or patella fracture is an uncommon but devastating complication after total knee arthroplasty. Various treatment options for repair of the extensor mechanism include observation, direct primary repair, direct primary repair with synthetic ligament or autogenous tissue augmentation, or reconstruction with allograft tissue. Recognition of the risk factors and prevention via meticulous surgical technique should be used in every patient undergoing TKA.

\section{Additional Information}

\section{Disclosures}

Human subjects: Consent was obtained by all participants in this study. Animal subjects: All authors have confirmed that this study did not involve animal subjects or tissue. Conflicts of interest: In compliance with the ICMJE uniform disclosure form, all authors declare the following: Payment/services info: All authors have declared that no financial support was received from any organization for the submitted work. Financial relationships: All authors have declared that they have no financial relationships at present or within the previous three 
years with any organizations that might have an interest in the submitted work. Other relationships: All authors have declared that there are no other relationships or activities that could appear to have influenced the submitted work.

\section{References}

1. Barrack RL, Stanley T, Allen Butler R: Treating extensor mechanism disruption after total knee arthroplasty. Clin Orthop Relat Res. 2003, 416:98-104. 10.1097/01.blo.0000092993.90435.69

2. Park SS, Kubiak EN, Wasserman B, Sathappan SS, Di Cesare PE: Management of extensor mechanism disruptions occurring after total knee arthroplasty. Am J Orthop (Belle Mead NJ). 2005, 34:365-72.

3. Crossett LS, Sinha RK, Sechriest VF, Rubash HE: Reconstruction of a ruptured patellar tendon with achilles tendon allograft following total knee arthroplasty. J Bone Joint Surg Am. 2002, 84-A:1354-61.

4. Siwek CW, Rao JP: Ruptures of the extensor mechanism of the knee joint. J Bone Joint Surg Am. 1981, 63:932-37.

5. Larsen E, Lund PM: Ruptures of the extensor mechanism of the knee joint. Clinical results and patellofemoral articulation. Clin Orthop Relat Res. 1986, 213:150-53.

6. Lynch AF, Rorabeck CH, Bourne RB: Extensor mechanism complications following total knee arthroplasty. J Arthroplasty. 1987, 2:135-40. 10.1016/S0883-5403(87)80020-7

7. Fernandez-Baillo N, Garay EG, Ordoñez JM: Rupture of the quadriceps tendon after total knee arthroplasty. A case report. J Arthroplasty. 1993, 8:331-33. 10.1016/S0883-5403(06)80097-5

8. Falconiero RP, Pallis MP: Chronic rupture of a patellar tendon: a technique for reconstruction with Achilles allograft. Arthroscopy. 1996, 12:623-26. 10.1016/S0749-8063(96)90204-2

9. Dobbs RE, Hanssen AD, Lewallen DG, Pagnano MW: Quadriceps tendon rupture after total knee arthroplasty. Prevalence, complications, and outcomes. J Bone Joint Surg Am. 2005, 87:37-45. 10.2106/JBJS.D.01910

10. Parker DA, Dunbar MJ, Rorabeck CH: Extensor mechanism failure associated with total knee arthroplasty: prevention and management. J Am Acad Orthop Surg. 2003, 11:238-47. 